\title{
Detecção de formas amastigotas em exame parasitológico de esfregaço obtido a partir de suabe conjuntival de cães com leishmaniose visceral
}

\author{
[Detection of amastigote forms in a parasitological exam of smears made from conjuntival swab in \\ dogs with visceral leishmaniasis] \\ V.T. Barbosa' ${ }^{1}$, M.A.G. Silva ${ }^{2}$, M.G. Sousa ${ }^{2}$, A.P. Gering ${ }^{1}$, H.D. Santos ${ }^{2}$, J.L. Laus ${ }^{3}$ \\ ${ }^{1}$ Aluno de pós-graduação - Faculdade de Ciências Agrárias e Veterinárias - UNESP - Jaboticabal, SP \\ ${ }^{2}$ Universidade Federal do Tocantins - UFT - Araguaína, TO \\ ${ }^{3}$ Faculdade de Ciências Agrárias e Veterinárias - UNESP - Jaboticabal, SP
}

\begin{abstract}
RESUMO
Leishmaniose é uma enfermidade multissistêmica cujas manifestações clínicas são extremamente variáveis. Em cães sinais clínicos oftálmicos são relativamente frequentes, ainda que outros sinais sistêmicos não sejam identificados. Atualmente, o diagnóstico da doença baseia-se em métodos parasitológicos, sorológicos e moleculares, mas, até o momento, a identificação de formas amastigotas desse parasito em esfregaços feitos a partir de suabes conjuntivais não é empregada rotineiramente. Valendo-se de cães sorologicamente positivos para leishmaniose, portadores (G1) ou não (G2) de alterações oftálmicas, este estudo avaliou a viabilidade do esfregaço a partir de suabe conjuntival como método de diagnóstico para a enfermidade. $\mathrm{O}$ exame suprarreferido foi positivo em $60 \%$ dos animais do G1 e $38,1 \%$ do G2, no entanto não houve diferença estatisticamente significativa em relação à positividade nos dois grupos $(\mathrm{P}=0,2167)$. Os dados apontam para uma tendência de os cães com leishmaniose e com sinais oftálmicos serem positivos ao exame parasitológico de esfregaço a partir de suabe conjuntival, podendo esse método ser útil no diagnóstico parasitológico da leishmaniose canina.
\end{abstract}

Palavras-chave: cão, Leishmania, linfonodo, conjuntiva

\begin{abstract}
Leishmaniasisis is a multisystemic disease with varying clinical presentations. In dogs, alterations in the eyes are commonly observed even in animals with no systemic signs. The diagnosis of leishmaniasis is currently based on parasitological, serological and molecular methods, although the identification of amastigote forms of this parasite in conjunctival swabs is not a routine technique in clinical practice. Serologically positive dogs for leishmaniasis presenting (G1) or not (G2) ocular alterations were enrolled in this study to evaluate the conjunctival swab as a method for the diagnosis of this disease. The parasitological evaluation of the swabs disclosed 60\% positivity for dogs in group 1, whereas only $38.1 \%$ of dogs in group 2 were positive. However, no significant difference was documented between the two groups $(P=0.2167)$. Our data suggest a tendency for dogs with ocular signs to be tested positive in the conjunctival swab exam, thus, this method is useful in the diagnosis of canine leishmaniasis.
\end{abstract}

Keywords: dog, Leishmania, lymph node, conjuntive

\section{INTRODUÇÃO}

As leishmanioses abrangem um amplo espectro de doenças transmitidas por insetos flebotomíneos infectados com parasitas do gênero Leishmania, podendo manifestar-se nas formas cutânea, mucocutânea ou visceral (Akilov et al., 2007). Segundo a Organização Mundial da Saúde (World, 2011), a doença ameaça 350 milhões de pessoas em 88 países do mundo, sendo 72 destes considerados países em desenvolvimento. 
O cão avoca importância quando se trata da epidemiologia da forma visceral da enfermidade por ser o principal reservatório dos parasitas (Deane e Deane, 1995) e considerado alvo em programas de erradicação da doença, à similitude do que ocorre com a raiva (Oliveira-dos-Santos et al., 1993).

Relativamente aos sinais clínicos, podem ser observados febre, perda de peso, atrofia muscular, vômito, diarreia, melena, hepatomegalia, esplenomegalia, linfadenopatia, dermatite granulomatosa ou ulcerativa, hiperceratose, descamação, úlceras mucocutâneas, onicogrifose, uveíte anterior, conjuntivite, blefarite, rinite, epistaxe, poliartrite neutrofílica, icterícia, dentre outros (Sherding, 2006). Não raro, cães infectados podem se apresentar assintomáticos (Sideris et al., 1999), entretanto, potencialmente infecciosos para o vetor (Moshfe et al., 2009).

Os testes sorológicos imunoenzimático (ELISA) e de imunofluorescência indireta (RIFI) são recomendados pelo Ministério da Saúde para o inquérito epidemiológico canino (Brasil, 2007), entretanto o exame parasitológico é considerado o teste de excelência para o diagnóstico da doença. A observação direta das formas amastigotas do parasito em esfregaços de aspirado de linfonodo, medula óssea, baço, fígado, pele e sangue corados por Giemsa, Leishman ou Panótico é uma forma segura, relativamente simples e rápida para o diagnóstico da enfermidade. A especificidade desse método é de $100 \%$, mas a sensibilidade depende do grau de parasitismo, do tipo de material biológico coletado, do seu processamento e coloração, além do observador. A sensibilidade pode ser de 50 a $83 \%$ em amostras de medula óssea, entre 30 a $85 \%$ em amostras de linfonodo e entre 71 a 91\% quando ambos os tecidos estão combinados (Laurenti, 2009). Considerando a possível variação no número de parasitos para cada amostra, o aumento do tempo de observação e no número de campos observados refletirá em maior sensibilidade para o teste (Maia e Campino, 2008).

A presença de sinais relacionados ao aparelho da visão em cães com leishmaniose não é incomum. Citações diversas imprimem a ocorrência de 16 a $80 \%$ de manifestações oculares em animais afetados (Molleda et al., 1993; Ciaramella et al., 1997; Koutinas et al., 1999; Peña et al., 2000).
Somada à avaliação clínica sugestiva de enfermidade sistêmica em curso, a presença do parasito já foi confirmada em exames histopatológicos de conjuntiva (Laugier e VerroBoulanger, 1992; Brito et al., 2010), esclera (Molleda et al., 1993), sistema lacrimal (Naranjo et al., 2005; Brito et al., 2010), trato uveal (Brito et al., 2010) e retina (Dias, 1998). Avaliações imunoistoquímicas oferecem importante valor diagnóstico por detectarem o agente mesmo em tecidos com baixo parasitismo (Tafuri et al., 2004), como já fora relatado por Brito et al. (2010) no tecido conjuntival, na túnica fibrosa e no trato uveal. Técnicas minimamente invasivas, como a execução de suabe conjuntival para detecção de Leishmania (L.) chagasi pela PCR, em cães, também mostraram seu valor diagnóstico (Ferreira et al., 2008). Formas amastigotas já foram observadas em esfregaços a partir de suabe conjuntival de animais infectados (Peña et al., 2000) e em citologia corneal (Brito et al., 2007).

Nesse contexto, o presente estudo teve o objetivo de avaliar a viabilidade do exame parasitológico em esfregaço feito a partir de suabe conjuntival de cães soropositivos para leishmaniose canina.

\section{MATERIAL E MÉTODOS}

Foram avaliados 41 cães com raça e idade variadas, machos e fêmeas, com média de peso igual a $12,0 \pm 7,0 \mathrm{~kg}$, sorologicamente positivos para Leishimania spp nos exames ELISA e RIFI. Os animais foram recolhidos para eutanásia, no cumprimento de exigência da Portaria Interministerial de 11 de julho de 2008, que proíbe o tratamento dessa enfermidade no país, obedecendo aos critérios éticos descritos na Resolução 714 do Conselho Federal de Medicina Veterinária, de 20 de junho de 2002, que dispõe sobre procedimentos e métodos de eutanásia em animais. Cuidados bioéticos relativamente às normas da Association for Research in Vision and Ophthalmology (ARVO) e da Comissão de Ética no Uso de Animais (CEUA) da Faculdade de Ciências Agrárias e Veterinárias UNESP/Jaboticabal (protocolo $\mathrm{n}^{\circ}$ 004173/11) foram rigorosamente obedecidos.

Após pesagem procedeu-se ao exame oftálmico com a execução sequencial, em ambos os olhos, das avaliações: teste lacrimal de Shirmer (Teste de Shirmer, Ophthalmos, Brasil), observação da 
região periocoular, avaliação dos reflexos pupilares à luz (direto e consensual), avaliação da câmara anterior, tonometria de aplanação após instilação de colírio anestésico (Anestésico, cloridrato de tetracaína $1 \%$ e cloridrato de fenilefrina $0,1 \%$ Allergan, Brasil), oftalmoscopia direta 20 minutos após instilação do colírio midriático (Mydriacy, tropicamida a $1 \%$, Alcon, Brasil) e, finalmente, o teste da fluoresceína (Fluoresceína Strips, Ophthalmos, Brasil).

Os sinais oftálmicos considerados como relacionados à leishmaniose visceral canina foram: teste de Shirmer com valor $\leq 10 \mathrm{~mm} / \mathrm{min}$; pressão ocular $\leq 15 \mathrm{~mm} / \mathrm{Hg}$; edema, hiperemia e alopecia palpebrais; hiperemia conjuntival; quemose; presença de secreção mucopurulenta ou purulenta; xerose, opacidade ou edema corneal; injeção ciliar; turbidez do humor aquoso; edema de íris e rubeosis iridis ou ambos. A apresentação de, no mínimo, três dos sinais descritos acima permitiu alocar o cão no grupo 1 - animais com intercorrências oftálmicas de significação clínica $(n=20)$ e a apresentação de até um desses sinais permitiu colocar o animal no grupo 2 - animais sem intercorrências oftálmicas dignas de nota $(n=21)$.

Findado o exame oftálmico, canulou-se a veia cefálica com cateter vascular (Angiocath, 22G, BD, EUA) para aplicação de acepromazina (Acepran 0,2\%, acepromazina, Univet, Brasil) na dose de $0,1 \mathrm{mg} / \mathrm{kg}$. Decorridos cinco minutos, também pela via intravenosa, procedeu-se à injeção de tiopental sódico (Tiopentax 1,0g, tiopental sódico, Cristália, Brasil) na dose média de $15 \mathrm{mg} / \mathrm{kg}$, como agente anestésico geral. Após delicada lavagem do saco conjuntival com solução fisiológica (Fisiológico 0,9\%, cloreto de sódio a $0,9 \%$, Equiplex, Brasil), utilizou-se uma pinça de conjuntiva para preensão e tração da face palpebral da conjuntiva da terceira pálpebra exteriorizando sua porção bulbar. Ato contíguo, realizou-se suave escarificação da porção exposta, bem como da região do fórnice conjuntival em toda sua circunferência, empregando-se suabe descartável estéril (Swab, suabe estéril, CB Products Ind. e Com. Ltda., Brasil). O material obtido foi depositado em movimentos de rolagem sobre uma lâmina de microscopia (Lâminas para microscopia com extremidade fosca, Exacta, Brasil) para exame parasitológico.

Realizou-se punção dos linfonodos mandibular, cervical superficial e poplíteo esquerdos, utilizando-se agulha descartável (Agulha descartável 0,70x25, BD, EUA), em movimentos regulares de avanço e recuo ao interior do órgão. O material obtido foi imediatamente depositado sobre lâmina para microscopia e distribuído sobre a mesma em forma de esfregaço.

Para o exame parasitológico, empregou-se o princípio de coloração estabelecida por Romanosvsky (Panótico rápido, LB, Brasil) e as lâminas foram avaliadas à microscopia de luz em lente de imersão com aumento de 1000x. A observação de uma única forma amastigota em quaisquer das lâminas refletiu resultado positivo para o animal em questão.

Foi realizado o teste exato de Fisher a partir dos dados observados nos dois grupos ao exame parasitológico. Calculou-se, ainda, a Odds ratio para determinação da razão de chance de um dado grupo ser positivo no exame parasitológico. Para essas análises, empregou-se o programa Graphpad Prism versão 5.03 para Windows (Graphpad Software®, San Diego, Califórnia, 2009).

\section{RESULTADOS}

A avaliação parasitológica de esfregaços a partir de suabe conjuntival mostrou positividade em $60 \%$ dos cães do grupo 1 e em $38,1 \%$ dos cães do grupo 2 (Tab. 1). A Odds ratio expressou valor igual a 2,438, no entanto, não houve diferença significativa entre os grupos estudados $(\mathrm{P}=0,2167)$.

Nas avaliações dos esfregaços oriundos das punções realizadas nos linfonodos, pôde-se observar a presença das formas amastigotas de Leishmania spp em pelo menos um dos linfonodos examinados (mandibular, cervical superficial e poplíteo) na totalidade dos exames do grupo 1 e em 95,5\% dos exames relativos ao grupo 2. 
Tabela 1. Resultado em frequência absoluta (n) e relativa (\%), positivo ou negativo, para Leishmania spp no exame parasitológico de esfregaço obtido a partir de suabe conjuntival em cães sorologicamente positivos para leishmaniose

\begin{tabular}{cccccccc}
\multirow{2}{*}{ Grupo } & \multicolumn{2}{c}{ Positivo } & \multicolumn{2}{c}{ Negativo } & \multirow{2}{*}{ Total } & Valor de $\mathrm{p}$ & Odds ratio \\
\cline { 2 - 5 } & $\mathrm{n}$ & $\%$ & $\mathrm{n}$ & $\%$ & & \\
\hline 1 & 12 & 60,0 & 08 & 40,0 & 100,0 & 0,2167 & 2,438 \\
2 & 08 & 38,1 & 13 & 61,9 & 100,0 & & $(0,6944$ a 8,556$)$ \\
\hline Total & 20 & 48,8 & 21 & 51,2 & 100,0 & - & - \\
\hline
\end{tabular}

Legenda - Grupo 1: animais com intercorrências oftálmicas de significação clínica; Grupo 2: animais sem intercorrências oftálmicas dignas de nota.

\section{DISCUSSÃO}

A conjuntiva ocular apresenta, em sua camada superficial, folículos linfoides que drenam para os linfonodos submaxilares e paratireoideos (Samuelson, 1998). Tal condição anatômica permite entender a razão de percentuais de positividade obtidos neste trabalho (Tab. 1). Os resultados são superiores aos 18,8\% (3/16) encontrados por Peña et al. (2000) ao realizarem a citologia de esfregaços conjuntivais em 16 cães com alterações oftálmicas decorrentes da leishmaniose.

Entre as estruturas oculares pesquisadas para Leishmania spp, a conjuntiva da terceira pálpebra tem demonstrado maior intensidade de parasitismo, como observado por Brito et al. (2010), que encontraram 92\% de animais positivos para Leishmania spp em exame histoquímico da terceira pálpebra, enquanto que em outros tecidos oculares a maior porcentagem foi de $24 \%$.

Quando comparados aos resultados do exame parasitológico com valores positivos em pelo menos um dos linfonodos avaliados (mandibular, cervical superficial ou poplíteo), a avaliação do esfregaço a partir de suabe conjuntival apresentou valores inferiores. No entanto, o exame do material colhido por suabe conjuntival pode ser utilizado como mais uma ferramenta de diagnóstico pelo clínico, principalmente em casos de lesões oculares constatadas em cães de áreas endêmicas.

Diferenças quanto à sensibilidade do exame parasitológico podem ser explicadas considerando-se o grau de parasitismo, o tipo de material biológico coletado, as variáveis de processamento e coloração, além da experiência do observador (Laurenti, 2009) e do tempo de observação (Maia e Campino, 2008).

O suabe conjuntival é uma técnica não invasiva e de rápida e fácil execução, como também relatado por Ferreira et al. (2008) e Leite et al. (2010). Essa é uma característica importante para utilização de um método de diagnóstico na clínica veterinária, pois minimiza a relutância dos proprietários quanto ao monitoramento periódico de seus animais. No presente trabalho, a coleta do suabe não suscitou nenhuma dificuldade, entretanto os animais encontravamse anestesiados.

Formas amastigotas de Leishmania spp foram identificadas em citologia de úlcera corneal por Brito et al. (2007). Andrade et al. (2006), após realizarem citologia de impressão da conjuntiva bulbar de cães com leishmaniose visceral canina, descreveram a técnica como factível para a avaliação da celularidade, entretanto não a indicaram como teste diagnóstico para a enfermidade.

Em estudos empregando esfregaço obtido a partir de suabe conjuntival para detecção do parasito pela PCR, foram encontrados resultados variando entre $66,6 \%$ e $83,3 \%$ em cães assintomáticos (Leite et al., 2010) e entre $52,2 \%$ e $73,9 \%$ em cães sintomáticos (Ferreira et al., 2008). Comparando com os resultados aqui observados e considerando que o exame parasitológico pode ser realizado de forma rápida e que não requer equipamentos especializados, pode-se recomendar esse método como uma forma útil de diagnóstico.

Como limitações da técnica empregada e em concordância com as citações de Laurenti (2009) e Maia e Campino (2008), destaca-se a 
experiência do observador e o tempo dispensado durante a leitura das lâminas como importantes fatores relacionados ao resultado da avaliação, ainda mais quando se trata de uma enfermidade cujo tratamento é proibido e a positividade no teste implica a eutanásia do paciente.

A impossibilidade da coleta de amostras negativas em animais nas mesmas condições daquelas empregadas no presente estudo, ou seja, anestesiados e sem qualquer dos múltiplos sinais clínicos relacionados à leishmaniose visceral canina em uma região endêmica para a enfermidade, invalidou a possibilidade de executar testes de sensibilidade para o exame de esfregaço a partir de suabe conjuntival.

\section{CONCLUSÕES}

O exame parasitológico de amostra coletada em suabe conjuntival pode ser uma ferramenta no diagnóstico da leishmaniose visceral canina. Trata-se de técnica não invasiva, de simples e rápida execução e de baixo custo. Contudo, a experiência do observador e o tempo considerado para as avaliações são fatores de suma importância para reforçar sua aplicabilidade e aceitabilidade na rotina clínica de pequenos animais.

\section{AGRADECIMENTOS}

Agradecemos à Coordenação de Aperfeiçoamento de Pessoal de Nível Superior pela bolsa concedida e a toda equipe do Centro de Controle de Zoonoses do município de Araguaína/TO pela colaboração especial durante a execução deste trabalho.

\section{REFERÊNCIAS}

AKILOV, O.E.; KACHEMOUNE, A.; HASAN, T. Clinical manifestations and classification of old world cutaneous Leishmaniasis. Int. J. Dermatol., v.46, p.132-142, 2007.

ANDRADE, A.L.; SANTO, E.F.E.; SAKAMOTO, S.S. et al. Citologia de impressão da superfície ocular de cães infectados naturalmente por Leishmania (L.) chagasi. Arch. Vet. Scie., v.14, p.9-16, 2009.
BRASIL. Ministério da Saúde. Secretaria de Vigilância em Saúde. Manual de vigilância da Leishmaniose Tegumentar Americana. 2.ed. Brasília, 2007. 181p. (Série A: normas e manuais técnicos).

BRITO, F.L.C.; ALVES, L.C.; MAIA, F.C.L. et al. Amastigota forms resembling Leishmania spp on corneal ulceration in a dog: case report. Arq. Bras. Med. Vet. Zootec., v.59, p.81-84, 2007.

BRITO, F.L.C.; LAUS, J.L.; TAFURI, W.L. et al. Histopathological findings and detection of parasites in the eyes of dogs infected naturally with Leishmania chagasi. Cienc. Rural, v.40, p.1141-1147, 2010.

CIARAMELLA, P.; OLIVA, G.; LUNA, R.D. et al. A retrospective clinical study of canine Leishmaniasis in 150 dogs naturally infected by Leishmania infantum. Vet. Rec., v.141, p.539543, 1997.

DEANE, L.M.; DEANE, M.P. Observações preliminaries sobre a importância comparativa do homem, do cão e da raposa (Lycalopex vetulus) como reservatórios da Leishmania donovani em área endêmica de calazar, no Ceará. O Hospital, v.48, p.79-98, 1955.

DIAS, D.V. Leishmaniose visceral canina: estudo parasitológico, imunológico e histopatológico em olhos de cães. 1998. 117f. Tese (Doutorado) - Escola de Veterinária, Universidade Federal de Minas Gerais, Belo Horizonte.

FERREIRA, S.A.; ITUASSU, L.T.; MELO, M.N.; ANDRADE, A.S.R. Evaluation of the conjuntival swab for canine visceral leishmaniasis diagnosis by PCR-hybridization in Minas Gerais State, Brazil. Vet. Parasitol., v.152, p.257-263, 2008.

KOUTINAS, A.F.; POLIZOPOULOU, Z.S.; SARIDOMICHELAKIS, M.N. et al. Clinical considerations on canine visceral leishmaniasis in Greece: a retrospective study of 158 cases (1989-1996). J. Am. Anim. Hosp. Assoc., v.35, p.376-383, 1999.

LAUGIER, C.; VERRO-BOULANGER, C. Ocular leishmaniasis. Prat. Med. Chirurg. Anim. Campag., v.27, p. 43-56, 1992. 
LAURENTI, M.D. Correlação entre o diagnóstico parasitológico e sorológico na leishmaniose visceral canina. Вера, v.67, p.1323, 2009.

LEITE, R.S.; FERREIRA, S.A.; ITUASSU, L.T. et al. PCR diagnosis of visceral leishmaniasis in asymptomatic dogs using conjunctival swab samples. Vet. Parasitol., v.170, p.201-206, 2010.

MAIA, C.; CAMPINO, L. Methods for diagnosis of canine leishmaniasis and immune response to infection. Vet. Parasitol., v.158, p.274-287, 2008.

MOLLEDA, J.M.; NOVALES, P.J.; GINEL, A. Clinical and histopathological study of the eye in canine leishmaniasis. Israel J. Vet. Med., v.48, p.173-178, 1993.

MOSHFE, A.; MOHEBALI, M.; EDRISSIAN, G. et al. Canine visceral leishmaniasis: Asyntomatic infected $\operatorname{dogs}$ as a source of $L$. infantum infection. Acta Trop., v.112, p.101-105, 2009.

NARANJO, C.; FONDEVILA, D.; LEIVA, M. et al. Caracterization of lacrimal gland lesions and possible pathogenic mechanisms of keratoconjuntivitis sicca in dogs with leishmanosis. Vet. Parasitol., v.133, p.37-47, 2005.

OLIVEIRA-DOS-SANTOS, A.J.; NASCIMENTO, E.G.; SILVA, M.P.; CARVALHO, L.C. Report on a visceral and cutaneous leishmaniasis focus in the town of Jequie, state of Bahia, Brazil. Rev. Inst. Med. Trop. São Paulo, v.35, p.583-584, 1993.
PEÑA, M.T.; ROURA, X.; DAVIDSON, M.G. Ocular and periocular manifestations of leishmaniasis in dogs: 105 cases (1993-1998). Vet. Ophthalmol., v.3, p.35-41, 2000.

SAMUELSON, D.A. Ophthalmic anatomy. In: GELLAT, K.N. 3th ed. Veterinary Ophthalmology. Baltimore: Lippincott \& Wilkins, 1998. p.31-150.

SHERDING, R.G. Toxoplasmose e outras infecções protozoarias sistêmicas. In: BIRCHARD, S.J.; SHERDING, R.G. 3th ed. Manual Saunders. New York: Elsevier, 2006. p.223-234.

SIDERIS, V.; PAPADOPOULOU, G.; DOTSIKA, E.; KARAGOUNI, E. Asymtomatic canine leishmaniasis in Greater Athenas area, Greece. Eur. J. Epidemiol., v.15, p.271-276, 1999.

TAFURI, W.L.; SANTOS, R.L.; ARANTES, R.M.E. et al. An alternative immunohistochemical method for detecting Leishmania amastigotes in paraffin-embedded canine tissues. J. Immun. Methods, v.292, p.17-23, 2004.

WORLD health organization. WHO. Programmes and projects. Leishmaniasis. Burden of disease. Disponível em: <http://www.who.int/leishmaniasis/burden/en/> Acessado em: 2 mar. 2011. 